NASA/TM-2004-213428

\title{
Reliability Issues in Stirling Radioisotope Power Systems
}

\author{
Ashwin R. Shah \\ Sest, Inc., Middleburg Heights, Ohio \\ Jeffrey G. Schreiber \\ Glenn Research Center, Cleveland, Ohio
}


Since its founding, NASA has been dedicated to the advancement of aeronautics and space science. The NASA Scientific and Technical Information (STI) Program Office plays a key part in helping NASA maintain this important role.

The NASA STI Program Office is operated by Langley Research Center, the Lead Center for NASA's scientific and technical information. The NASA STI Program Office provides access to the NASA STI Database, the largest collection of aeronautical and space science STI in the world. The Program Office is also NASA's institutional mechanism for disseminating the results of its research and development activities. These results are published by NASA in the NASA STI Report Series, which includes the following report types:

- TECHNICAL PUBLICATION. Reports of completed research or a major significant phase of research that present the results of NASA programs and include extensive data or theoretical analysis. Includes compilations of significant scientific and technical data and information deemed to be of continuing reference value. NASA's counterpart of peerreviewed formal professional papers but has less stringent limitations on manuscript length and extent of graphic presentations.

- TECHNICAL MEMORANDUM. Scientific and technical findings that are preliminary or of specialized interest, e.g., quick release reports, working papers, and bibliographies that contain minimal annotation. Does not contain extensive analysis.

- CONTRACTOR REPORT. Scientific and technical findings by NASA-sponsored contractors and grantees.
- CONFERENCE PUBLICATION. Collected papers from scientific and technical conferences, symposia, seminars, or other meetings sponsored or cosponsored by NASA.

- SPECIAL PUBLICATION. Scientific, technical, or historical information from NASA programs, projects, and missions, often concerned with subjects having substantial public interest.

- TECHNICAL TRANSLATION. Englishlanguage translations of foreign scientific and technical material pertinent to NASA's mission.

Specialized services that complement the STI Program Office's diverse offerings include creating custom thesauri, building customized databases, organizing and publishing research results ... even providing videos.

For more information about the NASA STI Program Office, see the following:

- Access the NASA STI Program Home Page at http://www.sti.nasa.gov

- E-mail your question via the Internet to help@sti.nasa.gov

- Fax your question to the NASA Access Help Desk at 301-621-0134

- Telephone the NASA Access Help Desk at 301-621-0390

- Write to:

NASA Access Help Desk

NASA Center for AeroSpace Information 7121 Standard Drive

Hanover, MD 21076 
NASA/TM-2004-213428

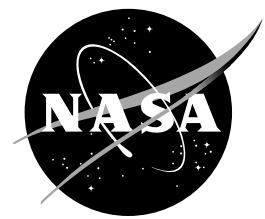

\title{
Reliability Issues in Stirling Radioisotope Power Systems
}

\author{
Ashwin R. Shah \\ Sest, Inc., Middleburg Heights, Ohio \\ Jeffrey G. Schreiber \\ Glenn Research Center, Cleveland, Ohio
}

Prepared for the

Second International Energy Conversion Engineering Conference

sponsored by the American Institute of Aeronautics and Astronautics

Providence, Rhode Island, August 16-19, 2004

National Aeronautics and

Space Administration

Glenn Research Center 


\section{Acknowledgments}

This work was performed for NASA Headquarters, Office of Space Science (Code S) under the Project Prometheus Program and was supported by the NASA Glenn Research Center Contract NAS3-03064.

Available from

NASA Center for Aerospace Information 7121 Standard Drive

Hanover, MD 21076
National Technical Information Service 5285 Port Royal Road Springfield, VA 22100

Available electronically at http:/ /gltrs.grc.nasa.gov 


\title{
Reliability Issues in Stirling Radioisotope Power Systems
}

\author{
Ashwin R. Shah \\ Sest, Inc. \\ Middleburg Heights, Ohio 44130 \\ Jeffrey G. Schreiber \\ National Aeronautics and Space Administration \\ Glenn Research Center \\ Cleveland, Ohio 44135
}

\begin{abstract}
Stirling power conversion is a potential candidate for use in a Radioisotope Power System (RPS) for space science missions because it offers a multifold increase in the conversion efficiency of heat to electric power and reduced requirement of radioactive material. Reliability of an RPS that utilizes Stirling power conversion technology is important in order to ascertain long term successful performance. Owing to long life time requirement (14 years), it is difficult to perform long-term tests that encompass all the uncertainties involved in the design variables of components and subsystems comprising the RPS. The requirement for uninterrupted performance reliability and related issues are discussed, and some of the critical areas of concern are identified. An overview of the current ongoing efforts to understand component life, design variables at the component and system levels, and related sources and nature of uncertainties are also discussed. Current status of the 110 watt Stirling Radioisotope Generator (SRG110) reliability efforts is described. Additionally, an approach showing the use of past experience on other successfully used power systems to develop a reliability plan for the SRG110 design is outlined.
\end{abstract}

\section{Nomenclature}

$\begin{array}{ll}\text { DOE } & \text { Department of Energy } \\ \text { GPHS } & \text { General Purpose Heat Module } \\ \text { GRC } & \text { Glenn Research Center } \\ R T G & \text { Radioisotope Thermoelectric Generator } \\ R E T & \text { Reliability Event Tree } \\ \text { SCA } & \text { Stirling Convertor Assembly } \\ \text { SRG110 } & 110 \text { watt Stirling Radioisotope Generator } \\ \text { SRG } & \text { Stirling Radioisotope Generator } \\ \text { SRPS } & \text { Stirling Radioisotope Power System } \\ T D C & \text { Technology Demonstrator Convertor }\end{array}$

\section{Introduction}

Decades of research on Stirling power conversion, and the ongoing joint efforts between the NASA Glenn Research Center (GRC) and the Department of Energy (DOE) to develop a free-piston Stirling radioisotope power system has made it possible to be considered as an energy conversion system option for future deep space science missions. The 110 watt Stirling Radioisotope Generator (SRG110) now under development has a multifold increase in efficiency and would reduce the inventory of the radioisotope fuel by a factor of 4 compared to the Radioisotope Thermoelectric Generators (RTGs) for an equivalent level of power. GRC has been involved in the development of Stirling power conversion technology for over 25 years and is currently providing technical support to DOE and their system integration contractor for the SRG110, Lockheed Martin, at Valley Forge, PA.

Owing to the requirement that any new radioisotope power system for NASA deep space missions perform efficiently without failure and maintenance for up to 14 years, high reliability is of paramount importance over the life of the mission. This includes prelaunch handling, assent, space flight, and possible descent to a planetary surface. The Stirling convertor is a free-piston device consisting of many components, materials, electronics, and heat exchangers. Flight development of the Stirling convertor would involve multiple disciplines. The convertor has minimal number of moving parts, and the design has eliminated and/or minimized all principal wear and life limiting mechanisms. As a result, there are key critical components, and the system as a whole, that need to be assessed to assure reliability. Additionally, the SRG110 that is being developed is a technology that does not have 
flight heritage as a power conversion system for the missions under consideration. Therefore, there are many issues related to the reliability quantification that must be investigated.

The SRG110 can be considered to consist of five (5) major components or subsystems such as the heat source, the Stirling power convertor, structure, radiator, and the controller electronics. Uncertainties in the design variables that affect the SRG110 reliability and an outline of the possible approaches for quantification have been discussed by Shah, et al. ${ }^{1}$ Accordingly, the reliability quantification of SRG110 involves analytical studies as well as component, sub-system and system level tests to ensure the desired performance objective and success of the power system. However, due to the long lifetime requirements, it is not practical to run long-term tests that simulate the actual operational conditions prior to a mission. Additionally, the SRG110 has been designed to eliminate all primary wear-out failures in the Stirling convertor. These are the same design approaches that were successfully used in the development of long-life cryocoolers, and similar challenges were faced in demonstrating long-life and reliability. However, the purpose of assuring the reliability is to ensure that the SRG110 will not experience malfunction or failure under any uncertain condition, material flaw or off-design operating condition that may be due to failure of electronics, control and sensors, or malfunction of any major components.

Possibility of failures always exists in any engineering design system. The occurrence of failures may be designed to be very rare, using high margins of safety, extensive testing, verification, quality control, inspections, etc. Therefore, as engineers, we know that certain failure modes do have a definite probability of occurrence and therefore affect the reliability of the system. A smart way of dealing with these design systems is to clearly understand the failure modes, scenarios that cause failures and apriori design remedial measures to address and reduce its impact on the overall performance without sacrificing the mission objectives, including mission safety. Understanding the issues related to the reliability of the Stirling Convertor Assembly (SCA) is key to the flight qualification, certification and mission success. This paper identifies potential issues affecting the Stirling Convertor Assembly reliability and progress that has been made in the early phase of reliability quantification.

\section{Stirling Radioisotope Power System}

The SRG110 consist of a radioisotope heat source,

Stirling convertor, structure, heat rejection system, and controller. The design, performance and reliability of the heat source, known as the General Purpose Heat Source (GPHS), which is provided by the Department of Energy is not in the scope of this paper. The salient features of the free-piston Stirling power convertor and the measures taken in the design and development to enhance reliability have been described in earlier publications. ${ }^{2}$ The specific Stirling convertor being transitioned for potential flight applications is the Technology Demonstration Convertor (TDC) that has been developed by the Stirling Technology Company of Kennewick, WA. ${ }^{3}$ The reliability of the TDC that would use the nominal $250 \mathrm{~W}$ of heat provided by a GPHS module is being quantified under the GRC technology development efforts (note that all current design and test activities are carried out using nonnuclear, surrogate heat sources). The reliability

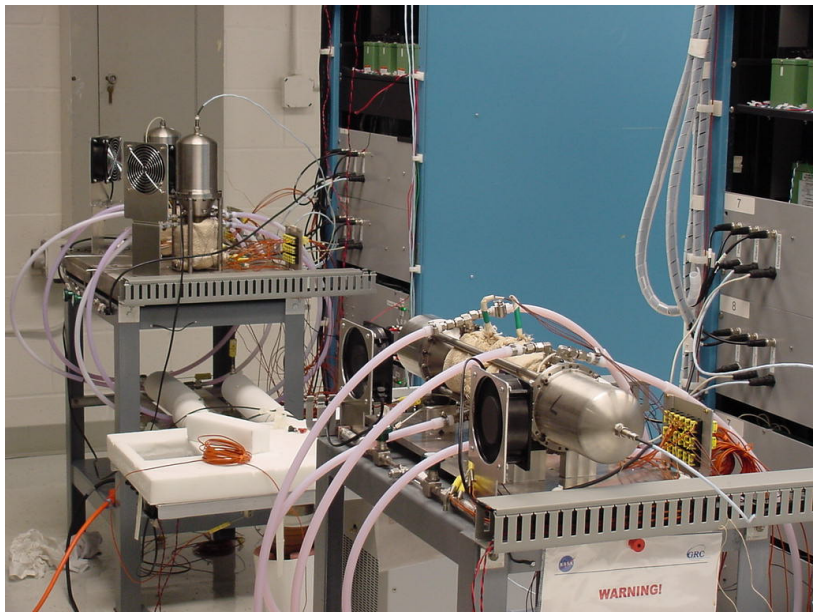

Figure 1.-Free-piston Stirling TDCs on test stands at GRC.

quantification process envisages the use of test data of at least four TDCs used in a range of tests at GRC, shown on test stands in figure 1, in addition to data from at least 12 other units under test at STC and LM. Critical components governing the performance and reliability of the TDC are the heater head, regenerator, displacer, flexures, fasteners, clearance seals, cooler, linear alternator (magnets, stators and coils), heat exchangers and the controller. The controller acts as a load for the convertor by processing the electrical power generated at the desired voltage to maintain the desired piston amplitude. In the process it also corrects the power factor of the power output, rectifies the alternating current (AC) power, and filters the output. The heat rejection system rejects the waste heat to space and performs a key function as the main structural element of the generator. Thus the reliability quantification of three subsystems namely; the Stirling convertor, heat rejection system and the controller forms the basis of SRG110 reliability. 
The SRG110 integrates two synchronously operated and dynamically balanced Stirling convertors in the dual-opposed configuration, each with their respective GPHS modules. A cutaway of the generator being developed by LM is shown in figure 2 . The power system for a mission would consist of one or more generators to achieve the required power level and possibly have a redundant generator if it is deemed necessary in the unlikely event of the failure of one SRG110. The reliability evaluation encompasses the operational presence of all the units and successful performance of the SRG110 from launch, throughout the mission, and including the possible landing on the surface of a planetary body.

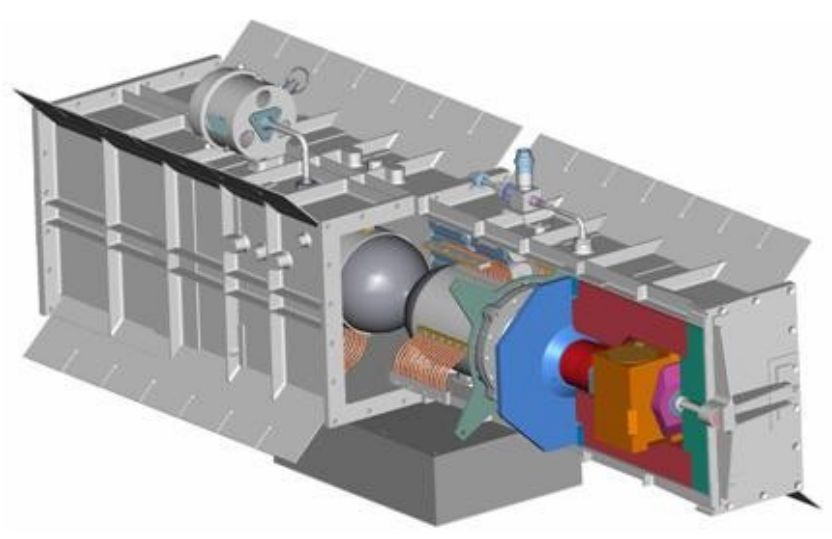

Figure 2.-Cutaway of the SRG with one Stirling Convertor and one GPHS module shown.

\section{Reliability of Stirling Convertor Components}

Within the SRG110, the SCA performs the function of converting thermal energy into electrical energy. Key components of the TDC, shown in figure 3, that dominate its reliability are the heater head, regenerator, displacer, flexures, fasteners, clearance seals, cooler, linear alternator assembly containing the magnets and stator laminations, heat exchanger and controller. Components and the integrated SCA are expected to have a life of up to 14 years or more for deep space missions. Mission success requires a reliable supply of uninterrupted power that meets all of the mission power quality requirements hinges on the reliability of these components. Some of the issues covering the reliability aspects of these components are discussed below.

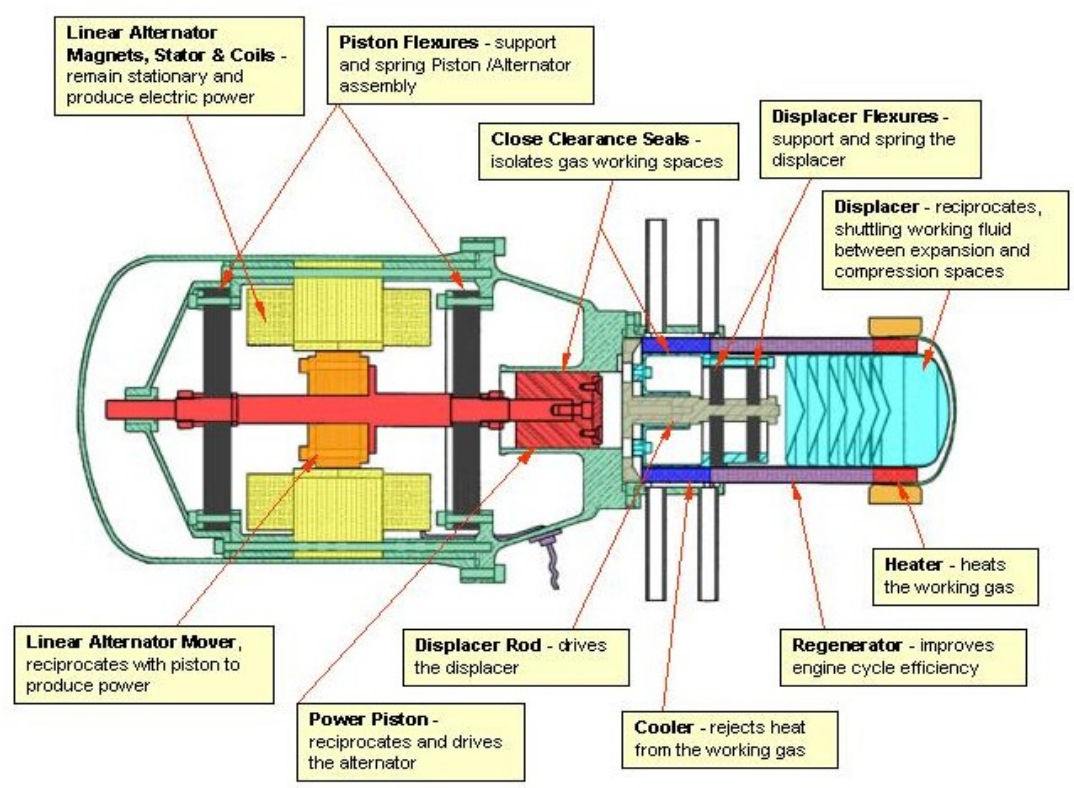

Figure 3.-TDC cross section with major components labeled.

\section{A. Heater Head}

The heater head is one of the most critical components of the convertor. It conducts heat from the GPHS module of the SRG110 and supplies it to the thermodynamic cycle. The structurally critical cylindrical heater head is made of thin section wrought Inconel 718 and must operate continuously at temperatures as high as $650{ }^{\circ} \mathrm{C}$. Creep resistance is the prime-durability concern. Creep resistances for wrought alloys generally increases dramatically with increasing grain size. However, there is a sharp decrease in creep resistance if the number of grains is less than about 20 across the stressed section. ${ }^{4}$ Therefore, the creep test data for various heats, heat treatments, and 
conventional product forms of Inconel 718 is not directly applicable to the heater head durability evaluation for this application. A reasonably large amount of creep test data from the Oak Ridge National Laboratory (ORNL) exhibits a large scatter in the life of Inconel 718 material. Also, the internally pressurized heater head (nominal 2.5-MPa) must not be allowed to distort excessively (or rupture) due to creep. The design variables governing the performance and life of the heater head will have uncertainties from different sources such as fabrication (geometry), environmental loads (pressure and temperature) and long-term creep behavior of the material (Inconel 718). Additionally, the heater head may experience a thermal excursion (possibly occurring due to failure in a control or sensor mechanism and taking time to correct the fault through health monitoring systems) of certain duration and magnitude during the mission that could affect the heater head life. Reliable durability evaluation of the heater head involves capturing these uncertainties.

A reliability assessment of the TDC heater head has been performed to evaluate the capabilities for long-term Space Science missions. ${ }^{5,6}$ The database on Inconel 718 generated by ORNL has been combined with data from tests $^{4}$ performed at NASA GRC on thin samples of the Inconel 718 to be used in the heater head. The purpose was to quantify uncertainties in the material behavior. Also, uncertainties in the geometry, pressure and temperature were included in the analysis. The assessment showed that the heater head has a life of 13.25 years with 99.99 percent probability of survival. For this analysis, end of life of the heater head was defined as the onset of tertiary creep, which is far short of a complete structural failure. Sensitivities of uncertainties in the material behavior, thickness, pressure and temperature were also quantified. As expected the heater head reliability is most sensitive to the uncertainties in the long-term creep behavior of Inconel 718. Also, the effect of possible thermal excursions on the heater head durability was investigated. The evaluation showed that thermal excursions up to $680{ }^{\circ} \mathrm{C}$ for durations up to 180 days, occurring within the first two years of mission life have, at most, a small effect on life. Evaluation of the effect of thermal excursions occurring in the later part of a mission, as well as more than one excursion during the life, need to be performed in a true probabilistic sense. Further comparison of computational results with the prototype short term accelerated tests in the laboratory is in the process to ascertain high reliability for term behavior.

\section{B. Alternator Flexure}

The flexure stack is another critical structural component of SCA and is required to undergo over 35 billion loading cycles during the 14 years of a planned mission without failure. Spiral geometrical configuration with one or more legs, with one end clamped at the stationary stator and other at the mover rod at the center provides a high radial stiffness and soft spring in the axial direction. The high radial stiffness allows maintaining non-contacting close clearance seal and provides linear motion without rocking. Use of flexures eliminates rubbing seals and lubrication, gas-bearing failures and provides good predictability, repeatability, reliability and stability as proven by its use in multiple space cryocoolers. Flexures used in many other applications have also demonstrated its efficiency, reliability, robustness, and safe operation over fairly good range of environmental conditions. SRG110 flexures are made from the highly fatigue resistant steel. Also, the flexures designed for SRG110 have undergone surface treatment such as shot peening in order to improve the fatigue life. However, like any material it is prone to the uncertainties in the manufacturing and fabrication process which affects its strength and long term behavior under cyclic loads known as fatigue strength. Since the fatigue strength of a material is a function of the stress level it is subject to, any scatter in the stress affects the fatigue life as well and as a result its reliability for desired life. The scatter in stresses is mainly derived from uncertainties in the material properties, geometry, loads and boundary conditions. Therefore, successful performance of flexures depends heavily on its long reliable fatigue life. Uncertainties in the flexure manufacturing and fabrication process, loading conditions and material strength need to be considered in the reliability assessment of the flexure fatigue life.

Generally the available fatigue tests are pure reversed bending for specimen geometry prepared using the American Society of Testing Materials (ASTM) guidelines. Cyclic reversed bending tests are easier to design and perform than cyclic axial fatigue tests. However, a multi-axial state of stress exists in the real components. Additionally, the probability of uncertainties in the fatigue life increases with the increase in size of components. Load factors have been applied to the results of bending test data to compare with the von-Mises (effective) stress in the components to assess the life and design components. Generally the load factor ranges between $07 \sim 0.9$. Determination of appropriate load factor for a given state of multi-axial stress is critical and requires careful attention. A reliability evaluation of SRG110 flexures has been performed considering the above uncertainties and the vendor supplied fatigue test data. Analysis using a load factor of 0.8 shows that the uncertainties (listed in the order of sensitivity) in the material fatigue strength, the piston stroke, elastic modulus and thickness of the flexure are most significant for 98.54 percent reliability. It means that the uncertainties in theses variables can be reduced to improve the reliability. Better quality control, stricter inspection procedures and testing could be implemented to 
have control over scatter in these variables. Also, flexure fatigue test data for flexures developed by STC for use in the other similar Stirling convertors is being studied to quantify the load factor more accurately for use in the reliability analysis. Past experience at STC suggests flexure being highly reliable for life over 10 years. ${ }^{7}$

\section{Linear Alternator}

The TDC linear alternator configuration uses stationary permanent magnets mounted on a stator to generate power. Excessive armature reaction to off design high temperatures, possible high armature current surges and oxidation may result in the partial demagnetization of permanent magnets and therefore the performance and reliability of the alternator. In order to achieve the desired performance and assure success of the power system, it is necessary to perform feasible tests on components, sub-system and system levels to validate the design. Since the linear alternator generates electrical energy using mechanical excitation of the mover and the magnetic field strength of the permanent magnets, it is one of the most critical components governing performance and reliability of the Stirling convertor, and the mission success of the power system.

The magnets are known to not degrade with time up to 15 years in the temperature range of $-30{ }^{\circ} \mathrm{C}$ to $150{ }^{\circ} \mathrm{C}$. However, the magnets do have uncertainties associated with their properties that affect the performance of the alternator. Additionally, the uncertainties associated with the geometry of the stator laminate assembly, the mover, the gap between mover and the magnet, etc. affect the performance of the alternator and ultimately the power output. Stirling linear alternator magnets are designed to operate in the temperature range and current amplitudes far away from the onset of demagnetization. However, the excursions of the temperatures for the reasons explained in the heater head section as well as currents spikes may occur during the mission and could push the conditions beyond the demagnetization boundary of magnets. The current spikes may be the results of some induced voltage spike due to controller malfunction or inductive load switching (such as motor or actuator turning on or off during the mission) or any atmospheric condition in space (similar to lightning). Although the inductance of the Stirling convertor is high enough to resist occasional voltage spikes of reasonable magnitudes, the uncertainties must be accounted for in the reliability evaluation of the magnets. A probabilistic evaluation of magnets and alternator using 3-D electromagnetic finite element analysis has already been performed and reliability assessment is in progress. The analysis shows that uncertainties in the permanent magnetization property and gap between the mover and piston have a significant impact on the reliability of output voltage. Analysis of the effect of current spikes is expected to start in near future as well. Effects due to oxidation, failure of epoxy bonds in stator laminates, etc. need to be included in the analysis as well.

\section{Fasteners}

The Stirling convertor is made up of several components joined together using fasteners and welds. Fasteners of critical importance are those between the piston housing and the heater head, the forward stator end ring to the aft stator end ring, the displacer spider to the piston housing, and the pressure vessel to the piston housing. Stirling convertor integrity to function as one unit is due to fasteners and welds that join different parts together. Although the fasteners are small but their significance to the integrity of the unit is very high, since it contributes to the deformation pattern and stresses in the components as well as could become a weak link leading toward failure under mission loads. Hence, the failure of fasteners or welds could impair the functionality of the convertor and result in mission failure.

Several important variables that impact the fastener behavior are the mission loads, fastener material properties, fastening process which involves amount of torque to be applied, sequence and pattern of applying the toques, friction between the contacting surfaces, o-rings, fretting of the parts being joined at the joining location, long term effect under deformation of the parts, etc. In addition to these, human error may also contribute to the fastener performance. Uncertainties associated with all these variables may influence fastener performance and could lead to possible failures affecting the reliability. Deterministic margin of safety does not provide it could vary under uncertainties. Fasteners could fail structurally or functionally. Considering the conservative nature of designs it may be possible that the fasteners may not fail structurally. However, if it becomes loose due to loss of friction through deformations, it could allow the parts to become loose, could cause vibratory effects in the structure, parts could loose clearance requirements, seals could become ineffective or make it prone to gas leakage, etc. and ultimately affect the performance. Excessive vibrations due to loose fasteners may result in convertor failure as well.

A detailed 3-D Finite Element Model (FEM) of the TDC, including different fasteners has been prepared at NASA GRC and a deterministic analysis has been performed. Sest, Inc. has started a reliability analysis using the 3-D FEM. Previously discussed uncertainties are included in the analysis and different possible failure will be considered in the reliability assessment. 


\section{E. Displacer Assembly}

The displacer assembly performs the function of transferring working fluid from the hot end to the cold end required to convert thermal energy in to electrical power. In order to achieve the functional requirement, the gap between the displacer assembly and the heater head cylinder wall, and the linearity of the motion must be maintained. The displacer assembly consists mainly of the displacer body, displacer rod, and the flexures mounted between them. Displacer assembly failure could result due to cyclic fatigue failure of the flexures, due to flexures loosing their spring rate, or contact between the displacer and either the displacer rod or the cylinder under abnormal vibration and/or shock loads with the lose of alignment. The loss of clearance between displacer and the cylinder wall could lead to contact that generated debris or changes the dynamics, and may result in power output reduction which may be considered to be a functional failure. The uncertainties in the fabrication (material manufacturing, part fabrication, assembly process, etc.) and the uncertainties described for the alternator flexures in section B contribute to the possible uncertainties in the behavior of displacer assembly, thus affecting its reliability. Therefore, reliability of displacer assembly is very critical to the reliable functioning convertor during the entire mission. The reliability analysis against the cyclic fatigue failure of displacer flexure is similar to that for the alternator. However, the reliability of the entire displacer assembly needs to be performed for other causes of failure.

\section{F. Regenerator}

The regenerator in the Stirling convertor performs a crucial role of transferring heat into and out of the working fluid during each cycle. A survey of Stirling convertors indicates that the pressure drop losses contribute 10 percent of the convertor thermal efficiency. ${ }^{8}$ The regenerator is made of thermally conductive material configured to have a large surface area to enable the heat transfer to and from the working fluid. The proposed regenerator for the SRG110 Stirling convertor uses random fiber material from a metallic alloy. The random arrangement of micro fibers provides open flow channels with a large surface area available and a minimum pressure drop. The desired arrangement of the fibers would provide thermal insulation or minimum thermal conduction in the axial direction and maximum radial conduction between the fibers. Random fiber regenerators are easy to fabricate and are cost effective. The flow friction is related to the heat transfer between the working fluid and the matrix. The randomness of the fibers is primarily in the plane perpendicular to the flow path and it enables heat transfer in the radial direction. Randomness of fibers could result in non-uniformity in the flow in random flow passages.

Due to the structural configuration, the thermal properties of the regenerator are random in nature and also the durability of the fibers could become an issue, such as in the case of shedding of fibers. Unsteadiness of the oscillatory flow influences the heat transfer and ultimately the efficiency of the convertor. The fluid mechanics and heat transfer behavior in regenerator is uncertain and/or difficult to characterize at macroscopic level under the oscillatory conditions. The porosity of the regenerator and the space between the regenerator and the heater and cooler heat exchangers (plenum thickness) are crucial to the efficiency of the regenerator. Eddy current flow formation in the porous media also changes heat dispersion properties. Considering the complicated nature of regenerator structure and its function, as well as possible effects of shedding, it is reasonable to perform a probabilistic evaluation of the regenerator and assess the long term reliability. Also, correlation with the test data measured at different levels of experiments are critical to validate and verify the quantified reliability. Long-term behavior of the materials is significant to the reliability of regenerator as well. Efforts in this direction are underway in collaboration with the regenerator technology development team head by NASA GRC.

\section{G. Launch Environment}

The Stirling convertor will be subject to steady g loads and random vibration while operating during the launch sequence. Abnormal and/or continuous vibrations could amplify the stresses and displacements in the components, impact the clearance requirements between components, and generate piston motions that could affect many other operational related issues. During the launch, the unit would be subject to $\mathrm{g}$ loads in different directions which could be random along with their amplitudes and frequencies. A random vibration test was performed for the TDC no. 1 in 1999, and further testing of a more advanced design is being planned. The random vibration test will increase in intensity until failure (failure based on the predefined failure criteria). Random responses of the unit will be measured, which can be used to model the random vibration behavior for the actual random mission loads in order to predict reliability.

\section{H. Electronics, miscellaneous parts and items}

Reliable performance and behavior of different components is also dependent upon the monitoring of system variables such as pressures and temperatures, using sensors and controls electronics. These items must be highly reliable and not induce unnecessary uncertainties. Therefore, reliability of sensors, controls, electronics, and other 
miscellaneous is equally critical items and must be quantified to ensure Stirling convertor reliability. Although standard techniques using MIL handbooks or IEEE guidelines could be used to quantify reliability, it is essential to ascertain that the modes of failures of these components that may not be covered by conventional methods be included in their reliability evaluation.

\section{Reliability Qualification Testing}

There are many computational approaches available to quantify the reliability. However, key to the validity and authenticity of these approaches largely hinges upon its comparison with the test data. Knowing the fact that performing tests for the mission time of 14 years or longer is not a practical proposition from viewpoint of time, cost and manpower, different methodologies that use short term component and system-level tests need to be developed and used to validate the computational approaches. Computational approaches that are planned and currently being used have been described by Shah, et al. ${ }^{1}$ These approaches are physics based that simulate uncertainties from the basics root level variables of the components. However, many challenging issues related to the testing remains to be addressed.

A logical approach would be to perform accelerated life testing at elevated environmental conditions that exceed levels for a typical planetary or deep space mission. The idea would be to induce failures resulting from design weaknesses over a reasonably short period of time. However, given the elimination of wear-out failure mechanisms in the TDC, accelerated tests may not reduce test time to a reasonable duration to accrue failures. The critical components for achieving long-life in a Stirling convertor do not have a common acceleration mechanism, and therefore accelerated life-tests of the convertor and/or system are not practical. Considering the highly integrated, multidisciplinary nature of the SCA, it is not clear that traditional accelerated life tests could be effectively used to predict the reliability of SCA for the mission.

In order to validate quantified reliability, one needs to determine how many tests and what kind of tests need to be performed. Probabilistic characterization of design variables requires many tests which is rarely possible, especially for the new materials and technology under development. Quantified sensitivities of design variables as well as statistical approaches such as Weibayes, design of experiments could used judiciously with logical engineering backup to determine the number and the nature of experiments to validate reliability

Many component level tests for the materials and devices have already been planned and performed to alleviate the issues related to reliability validation of the components. Some of these have already been used in the reliability analysis e.g. heater head material tests. Additionally the test data measured from the continuous operation of the TDCs no. 13 and 14 in the laboratory will be analyzed and compared with the computed system reliability. Also, probabilistic analysis of the GRC System Dynamic Model, which models the SRG110 from heat source to end-user load, could be used and compared with the test data measured in the laboratory for reliability prediction.

\section{Stirling Convertor Reliability}

The SCA is a multi-disciplinary system comprised of different components. Therefore, SCA reliability is a system reliability determined by using the reliability of each individual component together with the interaction of components and system performance functions. Developing functions that define the component interactions involving different disciplines is quite challenging. It involves defining how the performance of different components affects the system level performance. Based on interactions among components and subsystems, a Reliability Event Tree (RET) diagram can be prepared. Input to the RET diagram events will be individual component reliabilities, component interaction functions, probabilistic correlations among components and a system performance function. Obtaining probabilistic correlations as well as using them in the system reliability analysis is important to capture their impact on system reliability and sensitivity quantification. Several different approaches including the Monte-Carlo simulation can be used to perform the system reliability. Appropriate modeling could enable comparison of quantified reliability with the limited test data.

\section{Summary}

Key components of the SRG110 Stirling convertor impacting the reliability during the entire mission have been identified. Several major issues related to the reliability quantification of the Stirling convertor and its components have been described. Possible failure modes of different components and the Stirling convertor as a system have been described. Aspects of quantifying, validating and verifying the reliability of Stirling convertor components as well as the convertor as a system with the actual test data has also been described. Functions describing the interaction of the components and performance of the Stirling convertor have been shown to be important for the reliability assessment. Probability distributions of the component behavior together with performance functions 
modeling enable the reliability as well as sensitivity quantification. Importance of validating and verifying the quantified reliability with the limited available test data is discussed. Issues related to the number, nature and duration tests etc. to be performed, and their use in the reliability quantification has been discussed. A more through description of remaining issues not described in this paper is being prepared and will be published in the future.

\section{References}

${ }^{1}$ Shah A., Schreiber J., Zampino E., Best, T. "Reliability Assessment Approach for Stirling Convertors and Generators," in Proceedings of Space Technology and Applications International Forum (STAIF-2003), sponsored by the American Institute of Aeronautics and Astronautics, Albuquerque, New Mexico, February 2-5, 2003, pp. 648-655.

${ }^{2}$ Thieme, L.G., Schreiber, J.G., Mason, L.S., "Stirling Technology Development at NASA GRC," in proceedings of Space Technology and Applications International Forum (STAIF-2002), edited by M. El-Genk, AIP Conference Proceedings 608, New York, 2002, pp. 872-879.

${ }^{3}$ Qiu, S., Augenblick, J.E., White, M.A., Peterson, A.A., Redinger, D.L., and Petersen, S.L., "Developing a Free-Piston Stirling Convertor for Advanced Radioisotope Space Power Systems," in proceedings of Space Technology and Applications International Forum (STAIF 2002), edited by M. El-Genk, AIP Conference Proceedings 608, Melville, New York, 2002, pp. 912-917.

${ }^{4}$ Bowman, R.R., "Long-Term Creep Assessment of a Thin-Walled Inconel 718 Stirling Power-Convertor Heater Head," Paper CT-33, in Proceedings of the $36^{\text {th }}$ Intersociety Energy Conversion Engineering Conference, edited by D.M. Allen et al., IECEC Conference Proceedings, vol. 1, American Society of Mechanical Engineers, New York, 2001, pp. 435-440.

${ }^{5}$ Halford, G., Shah A., et al. "Structural Analyses of Stirling Power-Convertor Heater Head for Long-Term Reliability, Durability, and Performance," in Proceedings of Space Technology and Applications International Forum (STAIF-2002), sponsored by the American Institute of Aeronautics and Astronautics, Albuquerque, New Mexico, February 3-7, 2002, pp. 880-887.

${ }^{6}$ Shah A., Halford, G., et al. "Reliability Assessment of Stirling Convertor Heater Head," Presented at the Space Technology and Applications International Forum (STAIF-2004), sponsored by the American Institute of Aeronautics and Astronautics, Albuquerque, New Mexico, February 8-11, 2004.

${ }^{7}$ Qiu, S., Peterson A.A., Augenblick, J.E. "Flexure Design and Testing for STC Stirling Convertor," in Proceedings of $1^{s t}$ International Energy Conversion Engineering Conference, sponsored by the American Institute of Aeronautics and Astronautics, Portsmouth, VA, August 17-21, 2003.

${ }^{8}$ Tew, R.C., "DOE Regenerator Research Project Technical Meeting," presentation at Ohio Aerospace Institute, June 25, 2001, Periodicals 


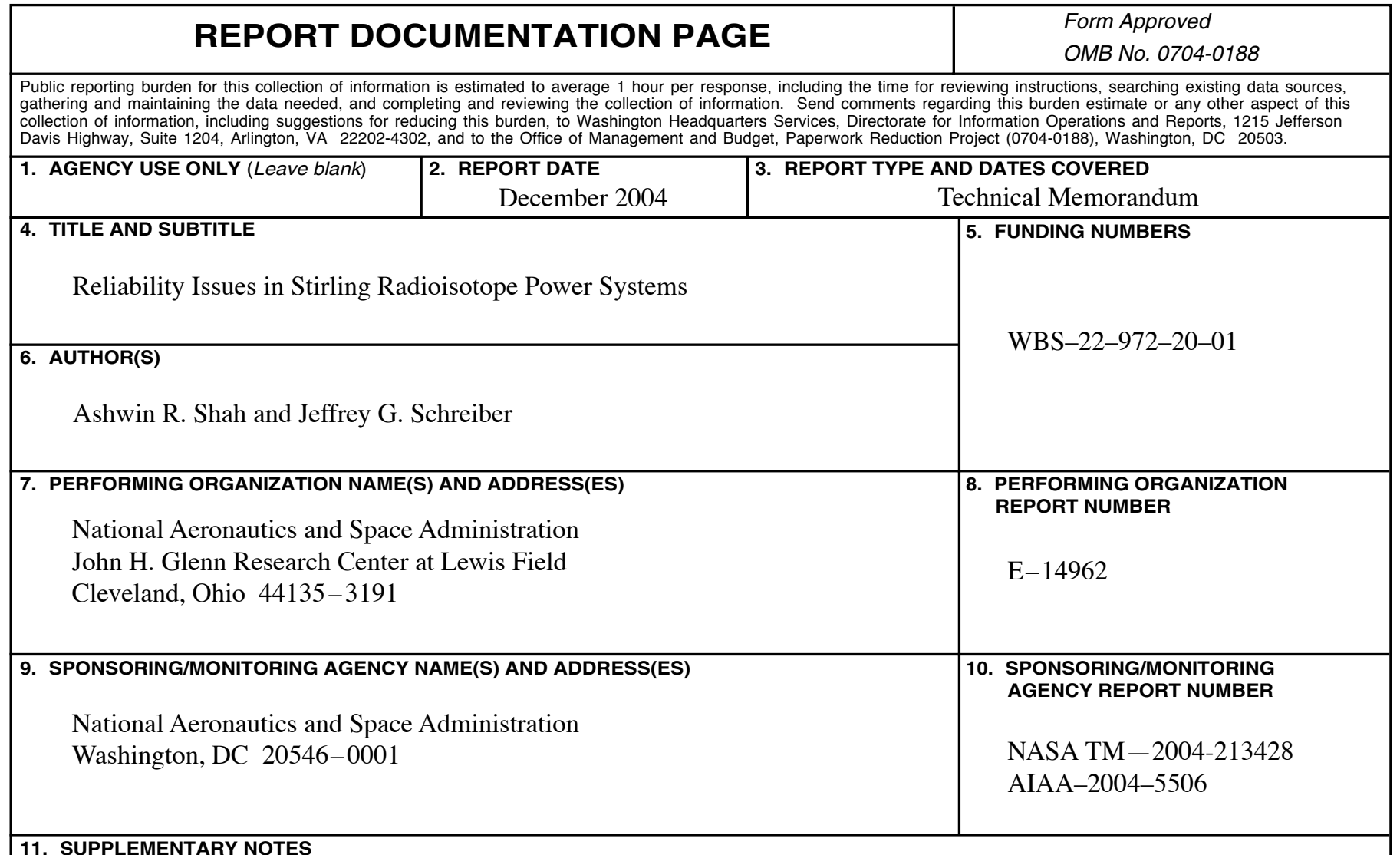

\section{SUPPLEMENTARY NOTES}

Prepared for the Second International Energy Conversion Engineering Conference sponsored by the American Institute of Aeronautics and Astronautics, Providence, Rhode Island, August 16-19, 2004. Ashwin R. Shah, Sest, Inc., Middleburg Heights, Ohio 44130; and Jeffrey G. Schreiber, NASA Glenn Research Center. Responsible person, Jeffrey G. Schreiber, organization code RPT, 216-433-6144.

12a. DISTRIBUTION/AVAILABILITY STATEMENT 12b. DISTRIBUTION CODE

Unclassified - Unlimited

Subject Categories: 20, 38, and 44

Distribution: Nonstandard

Available electronically at http://gltrs.grc.nasa.gov

This publication is available from the NASA Center for AeroSpace Information, 301-621-0390.

13. ABSTRACT (Maximum 200 words)

Stirling power conversion is a potential candidate for use in a Radioisotope Power System (RPS) for space science missions because it offers a multifold increase in the conversion efficiency of heat to electric power and reduced requirement of radioactive material. Reliability of an RPS that utilizes Stirling power conversion technology is important in order to ascertain long term successful performance. Owing to long life time requirement (14 years), it is difficult to perform long-term tests that encompass all the uncertainties involved in the design variables of components and subsystems comprising the RPS. The requirement for uninterrupted performance reliability and related issues are discussed, and some of the critical areas of concern are identified. An overview of the current on-going efforts to understand component life, design variables at the component and system levels, and related sources and nature of uncertainties are also discussed. Current status of the 110 watt Stirling Radioisotope Generator (SRG110) reliability efforts is described. Additionally, an approach showing the use of past experience on other successfully used power systems to develop a reliability plan for the SRG110 design is outlined.

\section{SUBJECT TERMS}

Stirling convertors

\begin{tabular}{|c|c|c|}
\hline $\begin{array}{c}\text { 17. SECURITY CLASSIFICATION } \\
\text { OF REPORT } \\
\text { Unclassified }\end{array}$ & $\begin{array}{c}\text { 18. SECURITY CLASSIFICATION } \\
\text { OF THIS PAGE } \\
\text { Unclassified }\end{array}$ & $\begin{array}{c}\text { 19. SECURITY CLASSIFICATION } \\
\text { OF ABSTRACT } \\
\text { Unclassified }\end{array}$ \\
\hline
\end{tabular}



